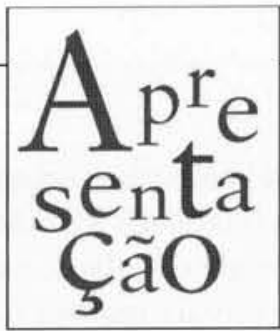

\title{
NOVAS TECNOLOGIAS, NOVAS SENSIBILIDADES
}

$\mathrm{D}$ urante muitas gerações aprendemos, nos bancos escolares, que pertencíamos a um território - o brasileiro -, com suas fronteiras e seus pontos geográficos mais avançados. Essa noção nos dava a substância de nossa identidade: nascidos nesse território, éramos brasileiros, comungávamos ideais com outros que nasceram no mesmo espaço, compartilhávamos a mesma cultura. Morávamos num bairro, víamos o tempo que passava ser contado pelo apito da fábrica, pelos sinos da igreja. Regendo-nos, o Estado Nacional.

Nos anos mais recentes, sobreveio a concepção de que as fronteiras haviam se dissolvido, graças às tecnologias. A velocidade - quer seja a referente aos meios de transporte rápido (qualquer capital do mundo está a poucas horas de nós), quer a que nos possibilita ver, em tempo real, na sala de nossa casa, acontecimentos que estão ocorrendo naquele momento em uma pequena aldeia de um país absolutamente distante - acopla-se à mudança da noção de espaço, resultando daí o que se designou desterritorialização. Como conseqüência, decreta-se a morte do Estado. O tempo já não se conta mais pelos apitos e pelos sinos.

\section{PROFESSORES E ALUNOS: NOVAS REALIDADES}

Para a sustentação desses conceitos contam muito os meios de comunicação.

Quando vemos nos meios de comunicação, em particular na televisão, as imagens de acontecimentos que estão ocorrendo bem longe de nós, sabemos que essas imagens foram editadas, ou seja, o que vemos é resultado de mediações, de escolhas. Sabemos que, ao selecionar-se uma imagem, descartaram-se várias outras. Ainda assim, nos envolvemos, tal é a força desse meio. Como lembra Marc Augé, fazendo considerações sobre espaço e tempo: "Além disso, é preciso constatar que se misturam diariamente

\section{A AUTORA}

Maria Aparecida Baccega

Professora Livre-Docente do Departamento de Comunicações e Artes da ECA-USP. Coordenadora do curso de Pós-graduação Gestão de Processos Comunicacionais (lato sensu). 
nas telas do planeta as imagens da informação, da publicidade e da ficção, cujo trabalho e cuja finalidade não são idênticos, pelo menos em princípio, mas que compõem, debaixo de nossos olhos, um universo relativamente homogêneo em sua diversidade. Existe algo mais realista e, num certo sentido, mais informativo, sobre a vida nos Estados Unidos que um boa série americana? Também seria preciso levar em consideração a espécie de falsa familiaridade que a telinha estabelece entre os telespectadores e os atores da grande história, cuja silhueta nos é tão habitual quanto aquela dos heróis das novelas ou das estrelas internacionais da vida artística ou esportiva. Eles são como as paisagens onde os vemos evoluir regularmente: o Texas, a Califórnia, Washington, Moscou, o Eliseu, Twickenham, os Pirineus ou o deserto da Arábia: mesmo que não as conheçamos, nós as reconhecemos"1.

É esse o modo que cada um de nós se crê cidadão do mundo, vivendo no pequeno espaço de seu bairro, de sua cidade. E considera, equivocadamente, que suas interpretações do que vê e do que vive são absolutamente individuais, próprias dele, originais.

Na verdade, falar em desterritorialização é exagero, uma vez que o Estado territorial continua a existir, sendo básico para impor as normas que regem o chamado processo de globalização, ou, no caso do Brasil, como diz Mílton Santos, sendo "mais duro do que o precedente regime autoritário na imposição de uma lógica internacional que desarticula as lógicas nacionais e não têm referência a uma lógica universal autêntica" . O território apenas mudou de face. O que existe são novas formas de vivenciar a identidade de pertencimento a um território. As anteriores foram totalmente modificadas pela tecnologia, pela comunicação, pelos novos conceitos de espaço e tempo. Criaram-se, desse modo, novas sensibilidades, novos modos de relacionar-se, maneiras diferentes de estar junto com outras pessoas, de circular pelas cidades.

Ocorre que, para os que viveram as realidades dos sinos e do apito da fábrica, que tinham como ponto de encontro as praças e os jardins, como lugar de compras o mercado, que viam como outro aquele que circulava fora desse espaço, para aqueles que se constituíram nessa vivência - no caso, a maioria dos professores -, é um processo bastante complexo relacionar-se cotidianamente no âmbito do projeto pedagógico, comunicar-se com aqueles que se formam enquanto cidadãos nessas realidades outras - os nossos alunos.

\section{DOS LUGARES AOS NÃO-LUGARES}

O Brasil, como de resto toda a América Latina, viveu, na segunda metade do século XX, um acelerado processo de urbanização que, segundo MartínBarbero, tem seu processo modernizador caracterizado por três dinâmicas dis-

1. AUGÉ, Marc. Não-lugares. Introdução a uma antropologia da supermodernidade. Campinas, São Paulo: Papirus, 1994. p. 34.

2. SANTOS, Mílton. Território, espaço banal, lugar-comum.. Jornal da Tarde. Caderno de Sábado, 9 de novembro de 1998. p.1-2. 
tintas e complementares. A primeira delas diz respeito à pressão para se conseguir melhores condições de vida, que vai da luta para se ter acesso aos equipamentos que caracterizam as cidades - água potável, espaços de lazer, habitação digna, educação etc. - até os que se referem efetivamente à participação cidadã, configurando novos modos de ação política (de que as Organizações Não-Governamentais são um exemplo). A segunda diz respeito à cultura do consumo, que, importada dos países centrais, revoluciona o comportamento e os estilos de vida, da alimentação à vestimenta, à diversão. E, finalmente, "as novas tecnologias comunicacionais, que pressionam para uma sociedade mais aberta $\mathrm{e}$ interconectada, que agilizam os fluxos de informações e as transações internacionais, que revolucionam as condições de produção e de acesso ao saber, mas ao mesmo tempo apagam memórias, transtornam o sentido do tempo e a percepção do espaço, ameaçando as identidades, pois é nelas que se configuram os imaginários em que se plasmam os novos sentidos que, em sua heterogeneidade, hoje cobrem tanto o local quanto os modos de pertencimento e reconhecimento que fazem a identidade nacional" ${ }^{3}$.

Nessa nova realidade, não mais as compras no mercado, o lazer nas praças: tudo se passa no shopping; não mais os encontros nos caminhos, nas ruas: a circulação é rápida, sem paradas, sem trocas com os outros. Tudo respondendo à nova realidade econômica mundial, efetivada "desde que se decidiu erigir em centro do universo não mais o homem, mas o dinheiro em estado puro, o que constitui uma enorme diferença de qualidade diante dos períodos capitalistas anteriores, nos quais o dinheiro se tornava capital produtivo, geografizando-se como capital produtivo e não apenas atravessando o espaço como fluido. Hoje é o dinheiro em estado puro que está presente na vida social e a comanda, ao mesmo tempo em que instala e agrava a fragilidade de tudo o que é territorial" 4 .

Marc Augé fala em não-lugares, que seriam os "espaços constituídos em relação a certos fins (transporte, trânsito, comércio, lazer) e a relação que os indivíduos mantêm com esses espaços" . Para esse autor, os não-lugares criam uma "tensão solitária", ou seja, a mediação do indivíduo com esses espaços se dá através de textos verbais ou imagéticos, com ordens e orientações como "pegar a fila da direita", "é proibido fumar", com sinais de trânsito ou as falas do caixa eletrônico quando usamos o cartão de crédito: "insira seu cartão", "digite sua senha", "limite diário de 600,00 " etc. Tais textos têm como enunciadores instituições: aeroportos e rodoviárias, bancos, polícia rodoviária, instituindo, desse modo, um novo modo de relacionamento social, uma nova prática de estar nos lugares, de vivenciar esses lugares. 


\section{UM NOVO SENSORIUM}

Essas transformações implicam, sobretudo no que se refere aos jovens, mudanças de sensibilidades, um novo sensorium, disponível para os chamados idiomas da tecnologia: a interação com a realidade, a vivência cultural, já não passa mais pelas falas animadas dos mercados em discussões sobre os preços ou pelas festas tradicionais de seu grupo; passa, isso sim, pela mediação do conectar-se ou desconectarse dos aparelhos, sempre com destaque para a televisão. Essas mudanças acarretam grande desconfiança por parte dos adultos. Afinal, trata-se de uma nova cultura, que produz saberes e habilidades fortemente distintos dos anteriormente exigidos. Daí a atribuir-se à tecnologia a responsabilidade maior para o que é descrito como "decadência de valores intelectuais e morais" da sociedade, é um passo muito pequeno. Falando dessa realidade, Martín-Barbero continua: "os jovens experimentam uma empatia feita não só de facilidade para relacionar-se com as tecnologias audiovisuais e informáticas, mas também de cumplicidade expressiva: é em seus relatos e imagens, em suas sonoridades, fragmentações e velocidades que eles encontram seu idioma e seu ritmo. Pois, frente às culturas letradas, ligadas à língua e ao território, as eletrônicas, audiovisuais, musicais ultrapassam essa limitação, produzindo comunidades hermenêuticas que respondem a novos modos de perceber e narrar a identidade. Identidades de temporalidades menos extensas, mais precárias, mas também mais flexíveis, capazes de amalgamar e fazer conviver ingredientes de universos culturais muito diversos" .

A manifestação dessas identidades se dá no cotidiano, espaço de relaxamento, de coexistência e cooperação, de intimidade, que possibilita a intersubjetividade. É o espaço da espontaneidade, da surpresa, da condição de reestruturar sistemas ideológicos constituídos. É ali que "a emoção tem lugar, e, por conseguinte, é ali somente onde pode se pensar o novo, já que o novo não se pensa fora da emoção"”.

Quando se reflete sobre essa temática, a impressão mais forte é aquela que diz que apenas o mundo influi sobre os lugares, numa relação de mão única, como se os lugares, os espaços de cotidiano dos grupos não tivessem importância, não significassem na nova realidade. Evidentemente, essa é uma falsa impressão.

Assim como, e já tratamos desse assunto várias vezes em nossa revista, ao pensarmos os meios de comunicação temos que enfocá-los não somente a partir da emissão, mas devemos levar em conta a recepção, aquela que se dá no âmbito desse cotidiano, com suas matrizes culturais, lugar, na verdade, onde se constroem os significados daquilo que é visto, ouvido ou lido, compondo o campo da comunicação, assim também devemos pensar as relações entre os lugares e o mundo: uma relação de interdependência, de trocas, de percursos cotidianos onde se inscrevem novos caminhos, "onde a emoção tem lugar", "onde pode se pensar o novo". Todos moramos num lugar e nele, com ele e a partir dele interagimos com o mundo, reconstruindo-o. 


\section{ARTIGOS NACIONAIS}

"O avanço acelerado das tecnologias tem alterado significativamente o modo de entender e perceber o mundo", diz Gelcivânia Mota Silva Morais. E como essa realidade chega ao contexto escolar? É do que ela trata em seu artigo Novas tecnologias no contexto escolar. Propondo que se abandone a visão dicotomizada entre homem e máquina, a autora lembra que "as tecnologias foram usadas, principalmente no espaço escolar, com a característica de um mero instrumento a serviço de uma formação castradora, rígida e congelada sob os pilares da disciplinaridade". Passando pela discussão de várias temáticas, inclusive o desemprego, a autora propõe que se pense um novo currículo, que ela chama de hipertextual, esperando que a escola tenha êxito no seu objetivo de formar cidadãos.

Como dissemos, todos moramos num lugar e nele, com ele e a partir dele interagimos com o mundo, reconstruindo-o. E para ampliar o universo cultural desse lugar que habitamos, o rádio tem sido de grande valia. Sobre isso escreve Nélia R. del Bianco, no artigo Rádio a serviço da comunidade. Ela retoma as rádios livres ou rádios populares por alto-falantes, manejadas por organizações populares e sindicais. "Além do caráter libertador de suas mensagens, esses setores mostraram novas e criativas formas de expressão e intercomunicação social, como a recriação da notícia, a recuperação da história oral da comunidade e a dramatização de situações do cotidiano". Tomando a "comunicação não como mero instrumento de transmissão de conhecimentos, mas processo cultural que agrega conflitos, contradições sociais e as práticas dos movimentos populares", a autora vai nos contar como o rádio foi usado, com êxito, na veiculação de programas de saúde.

Ainda no caminho do uso dos meios de comunicação voltados para a ampliação do universo cultural do lugar, apresentamos o artigo de Júlio Wainer, TV comunitária nos EUA. Trata-se de temática bastante oportuna, uma vez que estamos começando no Brasil a prática de TV comunitária. Lá existem cerca de "duas mil emissoras de tamanhos muito diferenciados. Há desde aquela que funciona em uma igreja, e que fecha às 18 horas, até centros que administram seis canais de televisão, rádio comunitária e centros de computadores de livre acesso pela população". Estas TVs são vistas "como ferramenta de transformação social" e colaboram, no âmbito escolar, para o desenvolvimento da alfabetização visual, levando o educando "a ler de forma crítica e também a escrever sua própria história e seus interesses".

Influências socioculturais na escolaridade de conscritos é o artigo de Leris S. B. Haeffner et al., que traz os resultados de pesquisa desenvolvida em Ribeirão Preto, com o objetivo de comparar a escolaridade dos pais e dos conscritos nascidos nos anos de 1978 e 1979, avaliando a relação entre a condição socioeconômico-cultural da família e o estágio de escolaridade atingido pelos filhos. Interpretando os dados a partir de confrontos com dados do IBGE, o artigo traz considerações sobre o acesso à escola e as possibilidades de êxito dos alunos. 


\section{ARTIGOS INTERNACIONAIS}

Dois dos maiores pesquisadores latino-americanos colaboram neste número da revista: Jesús Martín-Barbero e Guillermo Orozco Gómez.

Martín-Barbero, em Desafios culturais da comunicação à educação, relembra que "a TV não é vista como um meio para fazer/criar cultura, mas apenas para transmitir, difundir, divulgar". "Embora seja pelo rádio e, sobretudo, pela televisão que se efetuam, hoje em dia, algumas das mais profundas transformações na sensibilidade e na identidade das maiorias", as políticas de cultura ignoram o fato e a escola se aliena dessa realidade. $\mathrm{O}$ artigo discute com densidade essa questão, "a partir de duas dinâmicas: a de uma comunicação que se converte em ecossistema e a de uma forte diversificação e descentralização do saber".

Teleaudiência: premissas para uma pedagogia é o artigo de Guillermo OrozcoGómez. A preocupação fundamental aí discutida é "o tipo de conhecimento que se requer para interagir com a TV de maneira produtiva: uma maneira que possibilite aos telespectadores um encontro múltiplo, cada vez mais livre, autônomo, expressivo e, eventualmente, mais crítico". O autor propõe uma pedagogia da teleaudiência, que se diferencia da pedagogia da TV. Apresenta essa pedagogia e oferece um exercício a ser feito por alunos, em sala de aula.

\section{ENTREVISTA}

O entrevistado deste número é Renato Ortiz, autor de vários livros no campo da cultura e professor de Sociologia da Unicamp. Em Identidades culturais no contexto da globalização, Ortiz fala a Roseli Fígaro sobre as temáticas que tratam da globalização, das identidades culturais, da crise do Estado-nação, da tecnologia e das novas sensibilidades, entre muitas outras.

\section{CRÍTICA}

Ismail Xavier, em Cinema nacional: táticas para um tempo sem estratégias, apresenta-nos um panorama do cinema brasileiro nos últimos anos, comparando a produção cinematográfica contemporânea com a filmografia de décadas anteriores. Afirmando que não há na produção atual um tipo de contestação do passado recente, como aconteceu em períodos anteriores, o autor mostra o diálogo crítico entre essas produções.

\section{DEPOIMENTO}

Em Fascínio de trabalhar com livros, A. P. Quartim de Moraes nos fala das dificuldades de implantação de uma editora e dos prazeres de ver nascer um livro. 
Conta como trabalha desde a prospecção e desenvolvimento de uma obra até sua produção e comercialização.

\section{EXPERIÊNCIA}

As professoras do ensino fundamental Antônia Aparecida Justti e Sílvia Lúcia Silva Pinto relatam no artigo Exercício da dúvida no trabalho interdisciplinar como a postura pedagógica interdisciplinar, a partir do tema meio ambiente, tem desenvolvimento bastante proveitoso para os alunos. $\mathrm{O}$ processo de aprendizagem proposto faz com que os alunos desenvolvam métodos de levantamento de informações provenientes de fontes diferentes, tais como jornal da grande imprensa, experiência empírica, orientada pela professora, e dados da cultura popular.

\section{POESIA}

O cântico da terra, poesia de Cora Coralina, nos permite desfrutar uma pausa para pensar sobre a beleza das coisas simples e a importância da relação com a natureza.

\section{SERVIÇOS}

Newsware: proposta pedagógica de educação para a mídia, de Clóvis de Barros Filho, trata de uma nova página na Internet para a leitura crítica das notícias com a participação interativa dos leitores.

\section{VIDEOGRAFIA}

Maria Ignês Carlos Magno propõe uma releitura de dois períodos históricos do Brasil: mineração e imigração. A partir de uma seleção de filmes de ficção e documentários, a autora sugere uma reflexão sobre as comemorações dos 500 anos do Brasil.

\section{BOLETIM BIBLIOGRÁFICO}

Com a colaboração de Anamaria Fadul e Ismar de Oliveira Soares, respectivamente responsáveis pela Bibliografia sobre telenovela brasileira e Bibliografia sobre comunicação e educação, apresentam-se sugestões relevantes para a pesquisa e estudos desses temas. Endereços úteis na Internet traz mais uma série de sugestões de endereços de páginas com contribuições substanciais à pesquisa. 
Resumo: O artigo discute as mudanças na cultura contemporânea, advindas do processo de globalização; e como essas mudanças têm suscitado a discussão sobre as crises de identidade, principalmente aquelas calcadas no Estado nacional, evidenciando novas formas de se vivenciar a identidade de pertencimento a um território. Isso se dá ao mesmo tempo em que as novas tecnologias, a facilidade do fluxo de informações e a comunicação criaram novas sensibilidades, novos modos de as pessoas, principalmente os jovens, se relacionarem. Fato que tem aprofundado os desafios que a escola e o professor têm de enfrentar. A autora ressalta a importância, neste contexto, de se compreender essas novas tecnologias e os meios de comunicação a partir do ponto de vista da recepção, pois seus significados se constroem no cotidiano.

Palavras-chave: tecnologia, sensibilidade, campo da comunicação, território, identidade, cultura
Abstract: The article discusses the changes in contemporaneous culture that result from the globalization process and how these changes have brought on the discussion on identity crises, especially those based on the national State, presenting new manners to experience the pretencimento identity to a territory. This takes place at a time when the new technologies, the ease in information flow and communications create new sensibilities, new ways for people, especially young people, to relate with one another. This is a fact that has deepened the challenges that both school and teachers have to confront. The author emphasizes the importance, in this context, of understanding these new technologies and the means of mass communication from the reception point of view, since their meaning is built on the day-to-day basis.

Key words: technology, sensibility, field of communications, territory, identity, culture 